\title{
Galectin-3 as a novel biotarget in cardiovascular alterations associated to development of severe aortic stenosis
}

\section{La galectina-3, una nueva diana terapéutica para las alteraciones cardiovasculares asociadas al desarrollo de la estenosis aórtica severa}

https://doi.org/10.23938/ASSN.0643

V. Arrieta ${ }^{1,2}$, J.R. Sádaba ${ }^{1,2}$, V. Álvarez ${ }^{1,2}$, J.A. Rodríguez ${ }^{3,4}$, N. López-Andrés ${ }^{1,2}$

\begin{abstract}
Aortic stenosis is one of the most common heart valve diseases, as well as one of the most common causes of heart failure in the elderly. Currently, there are no medical therapies to prevent or slow the progression of the disease. When symptoms develop alongside severe aortic stenosis, there is a poor prognosis unless aortic valve replacement is performed. Aortic stenosis is a heterogeneous disease with a complex pathophysiology involving structural and biological changes of the valve, as well as adaptive and maladaptive compensatory changes in the myocardium and vasculature in response to chronic pressure overload. Galectin-3 serves important functions in numerous biological activities including cell growth, apoptosis, differentiation, inflammation and fibrosis. With evidence emerging to support the function of Galectin-3, the current review aims to summarize the latest literature regarding the potential of Galectin-3 as therapeutic target in aortic valve and cardiovascular alterations associated with aortic stenosis.
\end{abstract}

Keywords. Galectin-3. Aortic stenosis. Myocardial fibrosis. Valve calcification.

\section{RESUMEN}

La estenosis aórtica severa degenerativa (EA) es una enfermedad muy prevalente, cuya incidencia se incrementará en los próximos años debido al envejecimiento de la población. Actualmente no existe ningún tratamiento farmacológico que retarde su progresión y, cuando aparecen los síntomas, la cirugía de recambio valvular es la única opción. La EA se caracteriza por la calcificación de la válvula aórtica y por la aparición de fibrosis miocárdica. Sin embargo, no se conocen los mecanismos fisiopatológicos de la EA necesarios para identificar y desarrollar nuevas estrategias terapéuticas adecuadas. La Galectina-3 (Gal-3) regula funciones biológicas como el crecimiento, la diferenciación, la apoptosis, la inflamación o la fibrosis. Esta revisión resume los principales trabajos que describen el potencial de la Gal-3 como diana terapéutica para las alteraciones cardíacas y valvulares asociadas con el desarrollo de EA.

Palabras clave. Galectina-3. Estenosis aórtica. Fibrosis miocárdica. Calcificación valvular.
1. Navarrabiomed. Universidad Pública de Navarra.

2. Instituto de Investigación Sanitaria de Navarra. Pamplona. Spain.

3. Laboratory of Atherothrombosis. Program of Cardiovascular Diseases. Center for Applied Medical Research. University of Navarra. Pamplona. Spain.

4. CIBERCV. Madrid. Spain.

\section{Correspondencia:}

Natalia López-Andrés

Navarrabiomed

Irunlarrea 3

31008 Pamplona

España

E-mail: nlopezan@navarra.es

Recepción: 30/04/2019

Aceptación provisional: 31/05/2019

Aceptación definitiva: 10/06/2019 


\section{AORTIC STENOSIS}

Aortic stenosis (AS) is the most common heart valve disease (43\%) and represents a major healthcare burden, since it is the third leading cause of cardiovascular disease ${ }^{1}$. Risk factors include male gender, smoking, diabetes mellitus, hypertension, high levels of circulating lipids, and metabolic syndrome ${ }^{2}$. With the increase in the aging population, there is a surge in the prevalence of calcific aortic valve disease. A prediction on the number of elderly ( $\geq 70$ years) for the next few decades estimated that patients with severe AS will increase 2.4 fold by the year 2040 and more than triple by the year $2060^{3}$. Patients with AS have an $80 \%$ risk of valve replacement, progression to heart failure (HF), or death in the next 5 years after diagnosis ${ }^{4}$.

The aortic valve is composed of three leaflets attached to the fibrous ring at the outlet of the left ventricle. The leaflets are composed of a dense extracellular matrix usually delineated into three layers with diff erent matrix composition, populated with valve interstitial cells (VICs) and the entire structure covered by valve endothelial cells: lamina fibrosa is the widest layer and faces the aortic or arterial side of the valve cusp, and it is composed principally by collagen circumferentially oriented to provide tensile strength ${ }^{6}$; lamina spongiosa is rich in glycosaminoglycans and proteoglycans that are believed to confer flexibility, dampen vibrations from closing, and resist delamination ${ }^{7}$; lamina ventricularis is a dense sheet of elastic fibres on the inflow side of the valve that is compliant, and provides elasticity and preload to the leaflets ${ }^{8}$. During embryogenesis the endothelial cells covering the primordial valve cushions migrate inside the underlying matrix and undergo endothelial to mesenchymal transition to become the interstitial cells ${ }^{9}$.

The pathophysiology underlying calcific aortic valve disease remains incompletely defined and there are currently no effective medical treatments capable of altering its course $\mathrm{e}^{10}$. Chronic inflammation, fibrosis and calcification play an important role in the progression of the disease ${ }^{11}$. The aortic valve leaflets are a highly specialized structure consisting mostly of VICs and complex extracellular matrix structures ${ }^{12,13}$. An inflammatory and fibrotic process in aortic valve in humans and animal models has been previously reported ${ }^{14,15}$. Aberrant remodelling of the extracellular matrix is also caused by the deregulated overexpression of matrix metalloproteinases, associated with inflammation ${ }^{16}$. These events occur during the activation of VICs towards an osteogenic-like phenotype, promoted by the up-regulation of bone morphogenetic proteins pathway ${ }^{17}$. Therefore, it has been shown that calcific aortic valve disease shares features with vascular calcification and atherosclerosis such as chronic inflammation, increased extracellular matrix remodelling, proliferation and differentiation of VICs and the development of calcific lesions ${ }^{12,18}$. Of note, although retrospective studies had suggested that statins could delay the hemodynamic progression rate of $\mathrm{AS}^{19,20}$, in contrast, randomized controlled studies reported that a lipid-lowering strategy neither resulted in lower aortic valve-related events nor in a slower progression rate of stenosis ${ }^{21,22}$.

Moreover, chronic pressure overload in AS induces a structural remodeling of the left ventricle and may promote $\mathrm{HF}^{23}$ In the initial phases, the increased afterload imposed by aortic valve narrowing induces adaptive left ventricular hypertrophy that acts to maintain wall stress and cardiac output. Ultimately, this process decompensates, and patients transition from hypertrophy to HF and the development of symptoms and adverse cardiovascular events ${ }^{18}$. This transition is predominantly driven by myocardial fibrosis and myocyte cell death ${ }^{24}$. Thus, the transition from hypertrophy to HF plays a key role in AS. A better knowledge of the underlying mechanisms may highlight novel mediators of cardiac remodeling and decompensation which could identify biotargets for novel pharmacological therapies.

\section{GALECTIN-3}

Galectin-3 (Gal-3) is a $29-35 \mathrm{kDa}$ protein, member of a $\beta$-galactoside binding lec- 
tin family, localized in nucleus, cytoplasm, cell surface and extracellular space ${ }^{25}$. It is composed of a highly conserved N-terminal domain and a C-terminal carbohydrate recognition domain, which interacts with glycoproteins ${ }^{26}$. The damaging effects of Gal-3 have been associated to its capacity to bind matrix proteins such as cell surface receptors (integrins), collagen, elastin or fibronectin $^{27}$. The expression of this lectin has been reported in many tissues, including heart, vessels and kidney ${ }^{28}$. Moreover, Gal-3 is expressed in many cell types of the cardiovascular system such as cardiac fibroblasts $^{29}$, vascular smooth muscle cells ${ }^{30}$, endothelial cells ${ }^{31}$, VICs ${ }^{32}$ and inflammatory cells $^{33}$. Gal-3 is involved in numerous physiological and pathological processes some of which, inflammation and fibrosis, are pivotal contributing to pathophysiological mechanisms in the development and progression of HF.

The effects of Gal-3 in cells from the cardiovascular system have been largely investigated (Fig.1).

Indeed, it has been demonstrated in cell culture that Gal-3 turns quiescent fibroblasts into myofibroblasts that produce and secrete matrix proteins, including collagen ${ }^{29,34}$. Gal-3 exerts its effects during several other stages of fibrogenesis besides collagen production, such as collagen maturation and cross-linking, which underscores the pivotal importance of Gal-3 in cardiovascular fibro$\operatorname{sis}^{35,36}$. Moreover, Gal-3 has emerged as a potential mediator of cardiovascular damage

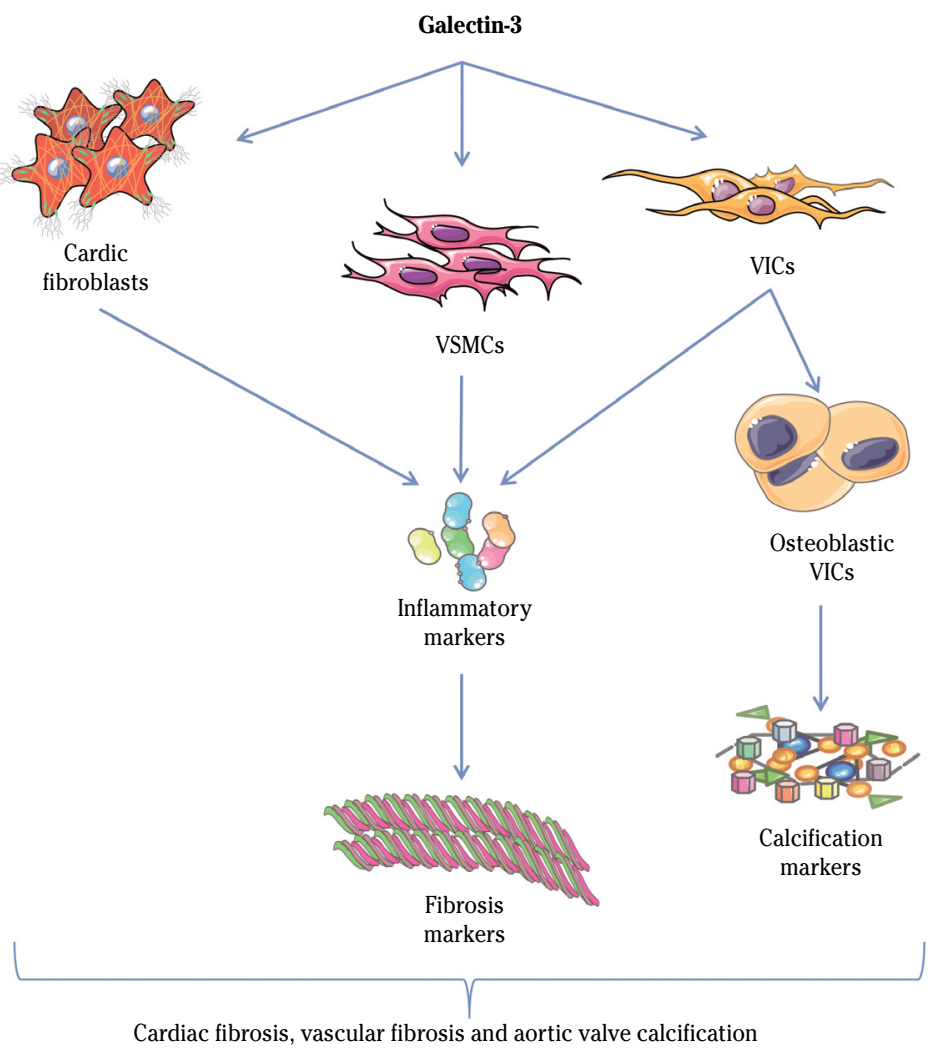

VCMCs: vascular smooth muscle cells; VICs: valve interstitial cells.

Figure 1. Involvement of Galectin-3 in cellular pathophysiological processes associated with aortic stenosis. 
in different pathological situations through its ability to stimulate key pro-inflammatory molecules ${ }^{33}$. Thus, it has been demonstrated in human cardiac fibroblasts that Gal-3 enhances the production and the secretion of proinflammatory and profibrotic mediators such as interleukin-1 $\beta$, IL-6, monocyte chemoattractant protein-1, collagen type I, collagen type III, fibronectin as well as the activity of metalloproteinases-1, -2 and $-9^{37}$. At the vascular level, Gal-3 increases the production and secretion of pro-fibrotic and pro-inflammatory markers in vascular smooth muscle cells $^{30}$, contributing to arterial stiffness. In endothelial cells, Gal-3 increases the expression of inflammatory factors (interleukin-6, interleukin-8, and interleukin-1 $\beta$ ), chemokines (monocyte chemoattractant protein-1) and adhesion molecules ${ }^{38}$. Furthermore, Gal3 modulates cell surface expression and activation of vascular endothelial growth factor receptor 2 in human endothelial cells contributing to the plasma membrane retention and exerting a pro-angiogenic function ${ }^{39}$. In VICs from aortic valves, Gal-3 also increases the secretion of pro-inflammatory and pro-fibrotic markers as well as the expression of calcification markers ${ }^{32}$.

\section{Beneficial effects of Galectin-3 blockade on aortic valve alterations in aortic stenosis}

Chronic pressure overload due to AS results in pathological morphological changes in the cardiovascular system. These changes result in an initially compensatory phase, whose persistance could produce an important impact on cardiovascular function ${ }^{40}$. Pressure overload induces a modification in the aortic valves and the valve cusps become progressively thickened, fibrosed and calcified $^{41}$. Moreover, a combination of endothelial damage and lipid deposition causes inflammation within the aortic valve that facilitates the infiltration of inflammatory cells which release proinflammatory factors ${ }^{42,43,44}$. In addition, matrix metalloproteinases secreted by VICs and inflammatory cells have an important and complex role in the restructuring of the aortic valve matrix ${ }^{43}$. Thus, abnormal remodeling in the aortic valve is also accompanied by the deregulated expression of metalloproteinases and inflammation ${ }^{16}$. As the stenosis-induced pressure overload progresses, wall shear stress across the aortic valve dramatically increase ${ }^{45}$, activating transforming growth factor- $\beta 1^{46}$, that can also induce fibrosis and calcification ${ }^{44}$.

Gal-3 expression has been recently reported in VICs from aortic valves in patients undergoing aortic valve replacement $^{32}$. Moreover, Gal-3 co-localized with the expression of osteogenic and inflammatory markers in human aortic valves ${ }^{32}$. Furthermore, in vitro, in human VICs, Gal-3 pharmacological inhibition with modified citrus pectin (MCP) as well as Gal-3 silencing attenuated the pro-inflammatory, pro-fibrotic and pro-osteogenic response ${ }^{32}$. A recent study described an association of Gal-3 with mortality after balloon aortic valvuloplasty, which is indicative of a contribution of local valvular Gal-3 expression to post-valvuloplasty restenosis ${ }^{47}$. In pressure overload, there is evidence of aberrant matrix deposition and valve fibrosis, which contributes to the calcification ${ }^{48}$.

In agreement with these data, AS animals presented increased aortic valve inflammation, fibrosis, metalloproteinase activities and calcification markers. The pharmacological inhibition of Gal-3 was able to decrease the aortic valve inflammation, fibrosis, metalloproteinase activities and calcification in absence of increased blood pressure levels in the pressure overload group, showing the potential therapeutic benefit of Gal-3 inhibition both in the primary (i.e., in early stages of pressure overload) and secondary prevention settings (i.e., when pressure overload is installed) (Fig. 2) ${ }^{49}$.

\section{Beneficial effects of Galectin-3 blockade on cardiac alterations in aortic stenosis}

AS accompanied by chronic pressure overload is a known precursor of left ventricular remodeling, involving cardiac fibrosis and inflammation. Patients display a marked variation in the magnitude of their 
Control
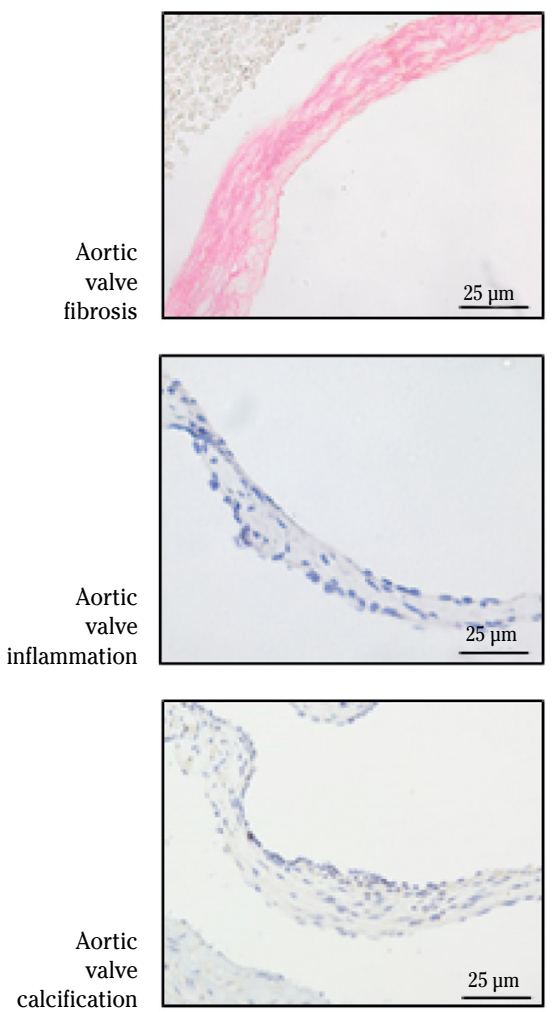

AS
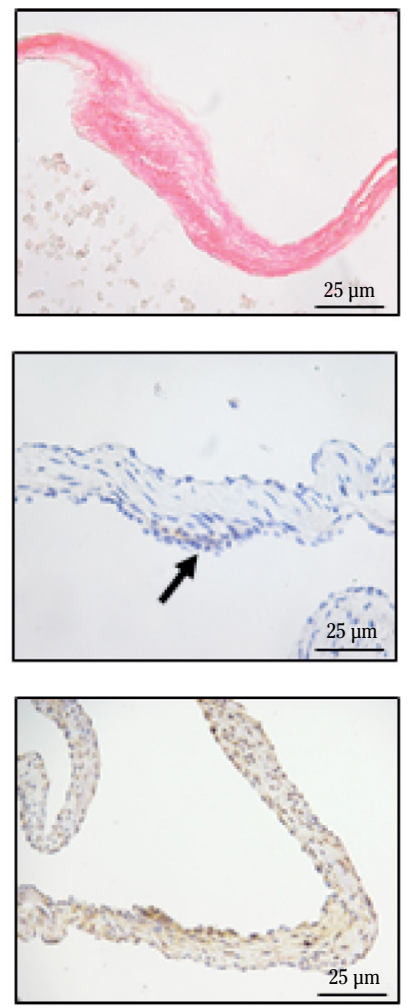

$\mathrm{AS}+\mathrm{MCP}$
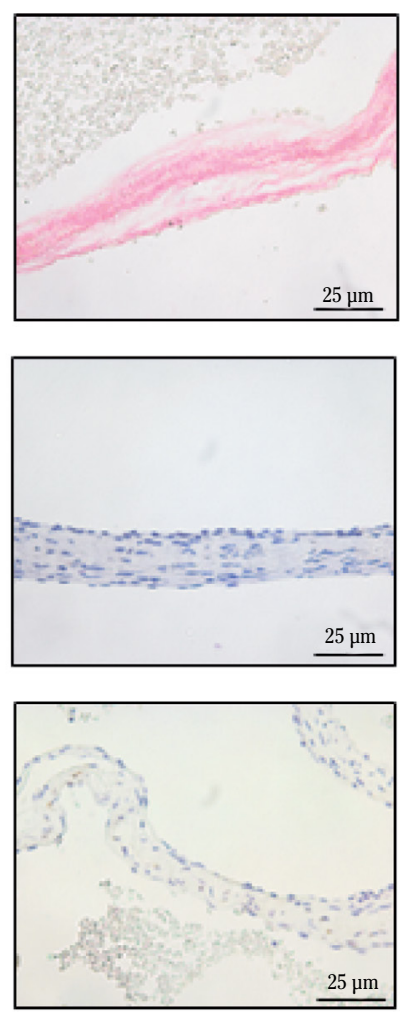

Figure 2. Beneficial effects of Galectin-3 blockade with modified citrus pectin (MCP) in aortic valve remodeling in an experimental model of aortic stenosis (AS). For collagen quantification (fibrosis), Sirius red staining was performed. Representative immunohistochemistry for cd68 and bone morphogenetic protein 4 are showed as examples of aortic valve inflammation and calcification respectively (from Ibarrola et al, 2017$)^{56}$.

left ventricular remodeling. This has recently been demonstrated to be of prognostic importance ${ }^{50}$. As with fibrosis in the valve, an imbalance in metalloproteinases and tissue inhibitor of metalloproteinase activities and inflammation have all been implicated in this process. In human myocardium, Gal3 is mainly expressed by cardiac fibroblasts and can be found in extracellular matrix ${ }^{51}$. Moreover, increased Gal-3 expression has been previously shown in myocardium from AS patients with depressed ejection fraction, as compared to myocardium from AS patients with preserved ejection fraction $^{29}$, suggesting a role for Gal-3 in cardiac dysfunction associated with AS. Besides, cardiac Gal-3 expression has been found to be increased in animal models of pressure overload $^{34,51,52}$ and paralleled the severity of left ventricular diastolic dysfunction ${ }^{52}$.

Several findings reported by our group deal with the potential consequences of Gal-3 overexpression in myocardium of AS patients. Firstly, cardiac Gal-3 overexpression is associated with cardiac fibrosis and inflammation ${ }^{51}$. Secondly, both cardiac and circulating Gal-3 levels positively correlated with cardiac fibrosis in AS patients ${ }^{53}$. Thirdly, a recent study showed that Gal-3 may serve as a prognostic biomarker after transcatheter aortic valve implantation by reflecting the degree of myocardial fibrosis $^{54}$. Additionally, cardiac Gal-3 expression is associated with inflammatory markers 
Control
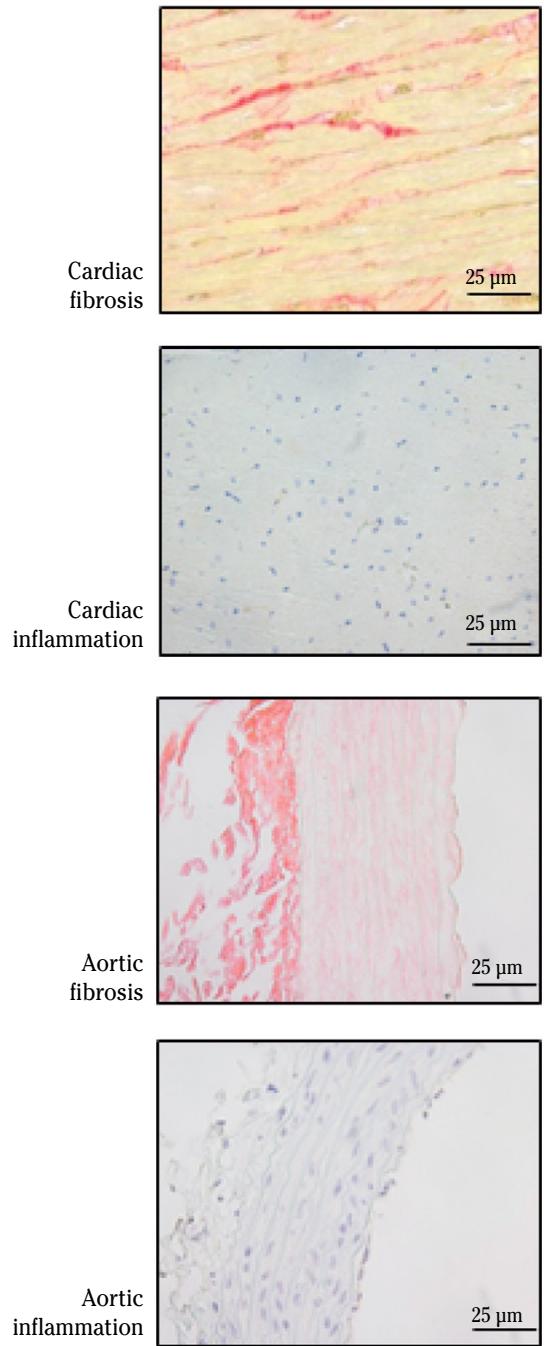

AS
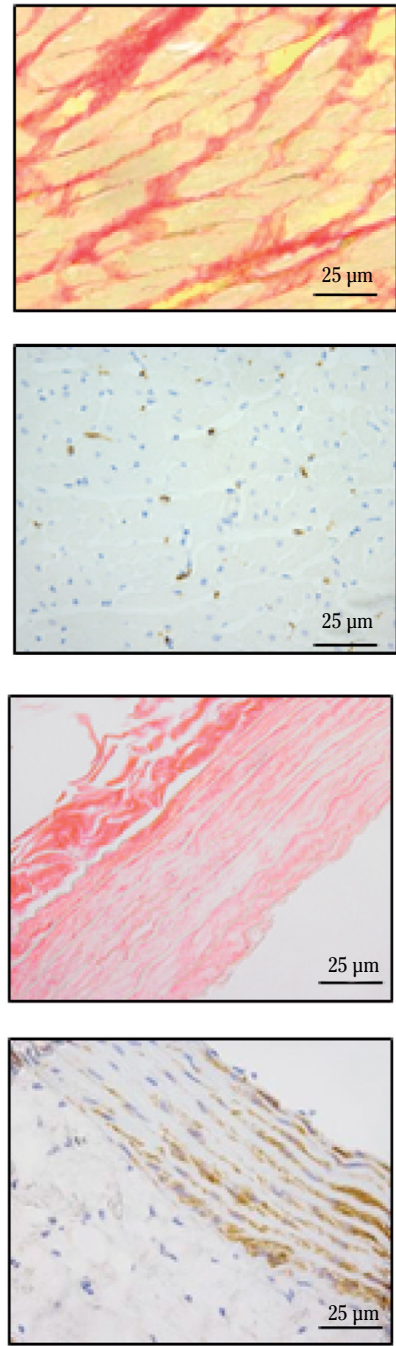

$\mathrm{AS}+\mathrm{MCP}$
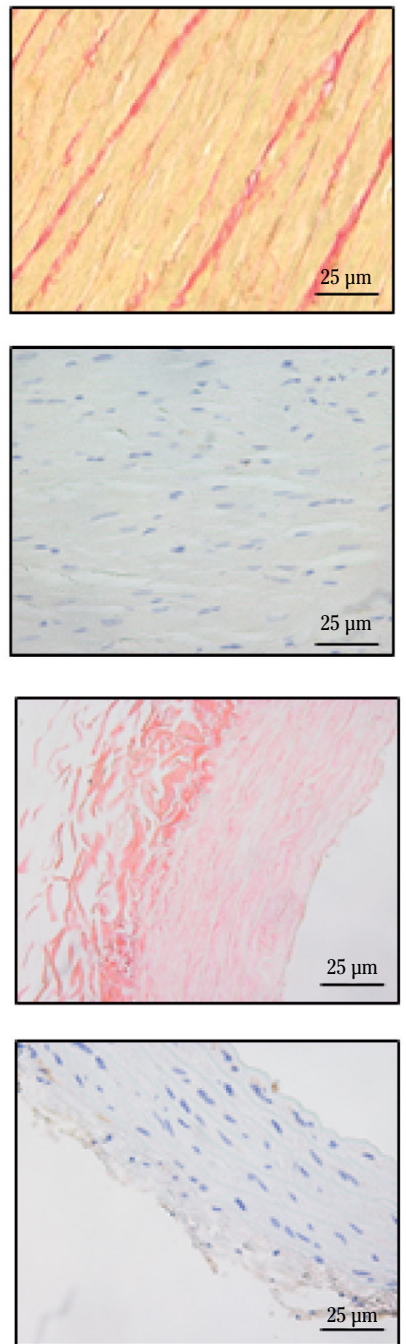

Figure 3. Beneficial effects of Galectin-3 blockade with modified citrus pectin (MCP) in cardiac and vascular remodeling in an experimental model of aortic stenosis (AS). For collagen quantification (fibrosis), Sirius red staining was performed in cardiac and aortic sections. In myocardium, cd68 was used as inflammatory marker, whereas in aortic sections monocyte chemoattractant protein-1 was chosen (from Ibarrola et al, $2017^{56}$ and Arrieta et al, $2017^{51}$ ).

and metalloproteinase-1 in myocardial biopsies from AS patients ${ }^{18}$, reinforcing the key role of this lectin in the inflammatory process and in extracellular matrix remodeling that accompanies the development of AS.

Previous studies have demonstrated that Gal-3 pharmacological inhibition pre- vented cardiac dysfunction, fibrosis and inflammation in several pathophysiological conditions such as hyperaldosteronism, ${ }^{37,55}$ obesity $^{37}$ or hypertension ${ }^{37}$. Similar beneficial effects have been reported on cardiac fibrosis, remodeling and dysfunction in Gal-3 knockout mice subjected to thoracic aortic constriction ${ }^{34}$. In line with these find- 
ings, pharmacological blockade of Gal-3 is able to prevent cardiac fibrosis, inflammation and functional alterations in an animal model of early stages of AS (Fig. 3). Thus, these results show the key role of Gal-3 in the cardiac remodeling associated with AS development and the beneficial effects of Gal-3 pharmacological inhibition on cardiac fibrosis and inflammation, the two key processes underlying the cardiac functional alterations which finally could affect cardiac function and AS progression, leading to HF.

\section{Beneficial effects of Galectin-3 blockade on vascular alterations in aortic stenosis}

At vascular level, pressure overload induces and increment of the aortic diameter and thickening of aortic wall through the extracellular matrix remodeling, characterized by an increment of fibrosis, inflammation and calcification in vessels and aortic valves ${ }^{45,46}$. Ascending aortic constriction is the most common surgical model for creating pressure overload-induced cardiovascular alterations. Gal-3 may contribute toward adverse cardiovascular effects in-part through an effect on aortic stiffness, effects which cannot be attributed to generalized inflammation.

In a recent study, it has been demonstrated that pharmacological Gal-3 inhibition by MCP could delay vascular remodeling and inflammation in a rat model of pressure overload (Fig. 3) ${ }^{51,56}$. Gal-3 inhibition exerts beneficial effects, decreasing aortic tunica media hypertrophy. Moreover, the use of MCP also decreases aortic fibrosis induced by pressure overload. Thus, the expression of collagen type I, fibronectin, $\alpha$-smooth muscle actin, transforming growth factor- $\beta 1$ and connective tissue growth factor was decreased in AS rats treated with the Gal-3 pharmacological inhibitor MCP. Complementarily, MCP treatment diminishes the expression of the inflammatory markers interleukin-6, interleukin-1 $\beta$, tumor necrosis factor- $\alpha$, monocyte chemoattractant protein-1, osteopontin, cd45 and cd68 in pressure-overloaded aortae (Fig. 3) ) $^{51,56}$. These results suggest that Gal-3 may contribute toward adverse cardiovascular effects in part through an effect on aortic stiffness. In line with these findings, it has been shown that Gal-3 also contributes to ventricular-vascular uncoupling in HF patients ${ }^{57}$.

\section{CONCLUSIONS}

Aortic stenosis is a disease of both the valve and the myocardium, characterized by fibrosis and calcification of valve leaflets, progressive left ventricular hypertrophy and cardiovascular fibrosis. In aortic stenosis, Gal-3 expression is increased in aortic valves, myocardium and aorta. Moreover, Gal-3 is colocalized with calcification markers in aortic valves, and with fibroblasts and extracellular matrix markers in myocardium. Gal-3 promotes inflammation, fibrosis and calcification in primary valvular interstitial cells and enhances the expression of fibrotic and inflammatory markers in cardiac fibroblasts and in vascular smooth muscle cells. Importantly, Gal-3 inhibition blocked aortic valve calcification, cardiac and vascular fibrosis and inflammation in vivo in an experimental model of pressure overload. Targeting Gal-3 may be an upstream therapeutic option for the treatment of aortic valve and cardiovascular remodeling that accompanies the progression of aortic stenosis. More in-depth mechanistic studies would be needed to understand the mechanisms by which Gal3 inhibition blocks cardiovascular damage in aortic stenosis. Further clinical studies are required to establish the potential therapeutic benefit of Gal-3 inhibition in aortic stenosis patients.

\section{BIBLIOGRAFÍA}

1. Iung B, Baron G, Butchart EG, Delahaye F, GohlKE-B̈̈RWOLF C, LEVANG OW et al. A prospective survey of patients with valvular heart disease in Europe: The Euro heart survey on valvular heart disease. Eur Heart J 2003; 24: 1231-1243. https://doi.org/10.1016/S0195668X(03)00201-X 
2. O'BriEn KD. Epidemiology and genetics of calcific aortic valve disease. J Investig Med 2007; 55: 284-291; https://doi. org/10.2310/6650.2007.00010

3 Danielsen R, Aspelund T, Harris TB, Gudnason $\mathrm{V}$. The prevalence of aortic stenosis in the elderly in Iceland and predictions for the coming decades: the AGES-Reykjavík study. Int J Cardiol 2014; 20: 916-922. https://doi. org/10.1016/j.ijcard.2014.08.053

4. Otto CM, Burwash IG, Legget ME, Munt BI, FuJIOKa M, Healy NL et al. Prospective study of asymptomatic valvular aortic stenosis. Clinical, echocardiographic, and exercise predictors of outcome. Circulation 1997; 6: 262-2270; https://doi.org/10.1161/01.CIR.95.9.2262

5. Misfeld M, Sievers H-H. Heart valve macro- and microstructure. Philos Trans R Soc Lond B Biol Sci 2007; 29: 1421-1436; https://doi. org/10.1098/rstb.2007.2125

6. Doehring TC, Kahelin M, Vesely I. Mesostructures of the aortic valve. J Heart Valve Dis 2005; 14: 679-686.

7. Stephens EH, Chu C-K, Grande-Allen KJ. Valve proteoglycan content and glycosaminoglycan fine structure are unique to microstructure, mechanical load and age: Relevance to an age-specific tissue-engineered heart valve. Acta Biomater 2008; 4: 1148-1160. https://doi. org/10.1016/j.actbio.2008.03.014

8. Helske S, Kupari M, Lindstedt KA, Kovanen PT. Aortic valve stenosis: an active atheroinflammatory process. Curr Opin Lipidol 2007; 18: 483-491. https://doi.org/10.1097/ MOL.0b013e3282a66099

9. ButCHER JT, NEREM RM. Valvular endothelial cells and the mechanoregulation of valvular pathology. Philos Trans R Soc B Biol Sci 2007; 29: 1445-1457. https://doi.org/10.1098/ rstb.2007.2127

10. Bossé Y, Migdad A, Fournier D, Pépin A, Pibarot P, Mathieu P. Refining molecular pathways leading to calcific aortic valve stenosis by studying gene expression profile of normal and calcified stenotic human aortic valves. Circ Cardiovasc Genet 2009; 2: 489-498. https:// doi.org/10.1161/CIRCGENETICS.108.820795

11. Mohler ER, Gannon F, Reynolds C, Zimmerman $\mathrm{R}$, Keane MG, Kaplan FS. Bone formation and inflammation in cardiac valves. Circulation 2001; 20: 1522-1528. https://doi. org/10.1161/01.CIR.103.11.1522

12. Bäck M, Gasser TC, Michel J-B, Caligiuri G. Biomechanical factors in the biology of aortic wall and aortic valve diseases. Cardiovasc Res 2013; 15: 232-241. https://doi.org/10.1093/ cvr/cvt040
13. Merryman WD, Youn I, LuKoff HD, Krueger PM, GullaK F, Hopkins RA et al. Correlation between heart valve interstitial cell stiffness and transvalvular pressure: implications for collagen biosynthesis. Am J Physiol Heart Circ Physiol 2006; 290: H224-231. https://doi. org/10.1152/ajpheart.00521.2005

14. Towler DA. Molecular and cellular aspects of calcific aortic valve disease. Circ Res 2013; 5 : 198-208. https://doi.org/10.1161/CIRCRESAHA. 113.300155

15. Miller JD, Weiss RM, Serrano KM, Brooks RM, BERRY CJ, Zimmerman K et al. Lowering plasma cholesterol levels halts progression of aortic valve disease in mice. Circulation 2009; 26 : 2693-2701. https://doi.org/10.1161/CIRCULATIONAHA.108.834614

16. Vanhoutte D, VAn Almen GC, VAn Aelst LNL, Van Cleemput J, Droogné W, Jin Y et al. Matricellular proteins and matrix metalloproteinases mark the inflammatory and fibrotic response in human cardiac allograft rejection. Eur Heart J 2013; 1: 1930-1941. https://doi.org/10.1093/ eurheartj/ehs375

17. Poggio P, Sainger R, Branchetti E, Grau JB, LAI EK, Gorman RC et al. Noggin attenuates the osteogenic activation of human valve interstitial cells in aortic valve sclerosis. Cardiovasc Res 2013; 1: 402-410. https://doi. org/10.1093/cvr/cvt055.

18. Dweck MR, Boon NA, Newby DE. Calcific Aortic Stenosis. J Am Coll Cardiol 2012; 6: 1854-1863. https://doi.org/10.1016/j.jacc.2012.02.093

19. Rajamannan NM, Subramaniam M, Springett M, Sebo TC, Niekrasz M, McConnell JP et al. Atorvastatin inhibits hypercholesterolemia-induced cellular proliferation and bone matrix production in the rabbit aortic valve. Circulation 2002; 4: 2660-2665. https://doi. org/10.1161/01.CIR.0000017435.87463.72.

20. Rajamannan NM, Subramaniam M, Stock SR, Stone NJ, SpRingett M, IgnATIEv KI et al. Atorvastatin inhibits calcification and enhances nitric oxide synthase production in the hypercholesterolaemic aortic valve. Heart 2005; 1: 806810. https://doi.org/10.1136/hrt.2003.029785

21. Chan KL, Teo K, Dumesnil JG, Ni A, Tam J, Astronomer Investigators. Effect of lipid lowering with rosuvastatin on progression of aortic stenosis: results of the aortic stenosis progression observation: measuring effects of rosuvastatin (ASTRONOMER) trial. Circulation 2010; 19: 306-314. https://doi. org/10.1161/CIRCULATIONAHA.109.900027.

22. Cowell SJ, Newby DE, Prescott RJ, Bloomfield P, ReId J, Northridge DB et al. A randomized trial of intensive lipid-lowering therapy in calcific 
aortic stenosis. N Engl J Med 2005; 352: 23892397. https://doi.org/10.1056/NEJMoa043876

23. MANN DL. Left ventricular size and shape: determinants of mechanical signal transduction pathways. Heart Fail Rev 2005; 10: 95-100. https://doi.org/10.1007/s10741-0054636-y

24. Hein S, Arnon E, Kostin S, Schönburg M, Elsässer A, Polyakova V et al. Progression from compensated hypertrophy to failure in the pressure-overloaded human heart: structural deterioration and compensatory mechanisms. Circulation 2003; 107: 984-991. https://doi. org/10.1161/01.CIR.0000051865.66123.B7

25. Dumic J, Dabelic S, FlöGel M. Galectin-3: an open-ended story. Biochim biophys acta. 2006; 1760: 616-635. https://doi.org/10.1016/j. bbagen.2005.12.020

26. Dennis JW, Pawling J, Cheung P, Partridge E, Demetriou M. UDP-N-acetylglucosamine:alpha-6-D-mannoside beta1,6 N-acetylglucosaminyltransferase V (Mgat5) deficient mice. Biochim Biophys Acta 2002; 19: 414-422. https://doi.org/10.1016/S0304-4165(02)00411-7

27. Ochieng J, FurTaK V, LukYanov P. Extracellular functions of galectin-3. Glycoconj J 2002; 19: 527-535. https://doi.org/10.1023/B:GLYC.0000014082.99675.2f

28. Kim H, Lee J, Hyun JW, Park JW, Joo H, Shin T. Expression and immunohistochemical localization of galectin-3 in various mouse tissues. Cell Biol Int 2007; 31: 655-662. https://doi. org/10.1016/j.cellbi.2006.11.036

29. Sharma UC, Pokharel S, van Brakel TJ, van Berlo JH, Cleutjens JPM, Schroen B et al. Galectin-3 marks activated macrophages in failure-prone hypertrophied hearts and contributes to cardiac dysfunction. Circulation 2004; 110: 3121-3128. https://doi.org/10.1161/01. CIR.0000147181.65298.4D

30. Calvier L, Miana M, Reboul P, Cachofeiro V, Martinez-Martinez E, de Boer RA et al. Galectin-3 mediates aldosterone-induced vascular fibrosis. Arterioscler Thromb Vasc Biol 2013; 33: 67-75. https://doi.org/10.1161/ATVBAHA. 112.300569

31. WAN SY, Zhang TF, Ding Y. Galectin-3 enhances proliferation and angiogenesis of endothelial cells differentiated from bone marrow mesenchymal stem cells. Transplant Proc 2011; 43: 3933-3938. https://doi.org/10.1016/j. transproceed.2011.10.050

32. Sádaba JR, Martínez-Martínez E, Arrieta V, Álvarez V, Fernández-Celis A, Ibarrola $J$ et al. Role for galectin-3 in calcific aortic valve stenosis. J Am Heart Assoc 2016; 5. https://doi. org/10.1161/JAHA.116.004360
33. Papaspyridonos M, McNeill E, de Bono JP, Smith A, Burnand KG, Channon KM et al. Galectin-3 is an amplifier of inflammation in atherosclerotic plaque progression through macrophage activation and monocyte chemoattraction. Arterioscler Thromb Vasc Biol 2008; 28: 433-440. https://doi.org/10.1161/ATVBAHA.107.159160

34. Yu L, Ruifrok WPT, Meissner M, Bos EM, van Goor H, SANJabi B et al. Genetic and pharmacological inhibition of galectin-3 prevents cardiac remodeling by interfering with myocardial fibrogenesis. Circ Heart Fail 2013; 6: 107-117. https://doi.org/10.1161/CIRCHEARTFAILURE.112.971168

35. Ho MK, SPRINGER TA. Mac-2, a novel 32,000 Mr mouse macrophage subpopulation-specific antigen defined by monoclonal antibodies. J Immunol 1982; 128: 1221-1228.

36. De Boer RA, van der Velde AR, Mueller C, van Veldhuisen DJ, AnKer SD, Peacock WF et al. Galectin-3: A Modifiable risk factor in heart failure. Cardiovasc Drugs Ther 2014; 28: 237-246. https://doi.org/10.1007/s10557-014-6520-2

37. Martínez-Martínez E, López-ÁNDRes N, JuRAdo-López R, Rousseau E, Bartolomé MV, FernánDEZ-CELIS A et al. Galectin-3 participates in cardiovascular remodeling associated with obesity. Hypertension 2015; 66: 961-969. https://doi.org/10.1161/HYPERTENSIONAHA. 115.06032

38. Chen X, Zhang R, Zhang Q, Xu Z, Xu F, Li D et al. Microtia patients: Auricular chondrocyte ECM is promoted by CGF through IGF-1 activation of the IGF-1R/PI3K/AKT pathway. J Cell Physiol 2018. https://doi.org/10.1002/ jcp. 27316

39. Markowska AI, JefFeries KC, Panjwani N. Galectin-3 protein modulates cell surface expression and activation of vascular endothelial growth factor receptor 2 in human endothelial cells. J Biol Chem 2011; 25: 29913-29921. https://doi.org/10.1074/jbc.M111.226423

40. Gs AK, Raj B, Santhosh KS, Sanjay G, Kartha CC. Ascending aortic constriction in rats for creation of pressure overload cardiac hypertrophy model. J Vis Exp 2014; e50983. https:// doi.org/10.3791/50983

41. Mourino-Alvarez L, Baldan-Martin M, Gonzalez-Calero L, Martinez-Laborde C, Sastre-Oliva T, Moreno-Luna R et al. Patients with calcific aortic stenosis exhibit systemic molecular evidence of ischemia, enhanced coagulation, oxidative stress and impaired cholesterol transport. Int J Cardiol 2016; 225: 99-106. https://doi.org/10.1016/j.ijcard.2016.09.089 
42. Kaden JJ, Dempfle C-E, Grobholz R, Tran H-T, Kiliç $\mathrm{R}$, SARIKOÇ A et al. Interleukin-1 beta promotes matrix metalloproteinase expression and cell proliferation in calcific aortic valve stenosis. Atherosclerosis 2003; 25: 205-211. https:// doi.org/10.1016/S0021-9150(03)00284-3

43. Malek AM, Gibbons GH, Dzau VJ, Izumo S. Fluid shear stress differentially modulates expression of genes encoding basic fibroblast growth factor and platelet-derived growth factor B chain in vascular endothelium. J Clin Invest 1993; 1: 2013-2021. https://doi. org/10.1172/JCI116796

44. Laurent S, Boutouyrie P, Asmar R, Gautier I, Laloux B, Guize L et al. Aortic stiffness is an independent predictor of all-cause and cardiovascular mortality in hypertensive patients. Hypertens (Dallas, Tex 1979); 2001; 25: 1236-1241; https://doi.org/10.1161/01. HYP.37.5.1236

45. Gould ST, SRigunapalan S, Simmons CA, Anseth KS. Hemodynamic and cellular response feedback in calcific aortic valve disease. Circ Res 2013; 5: 186-197. https://doi.org/10.1161/ CIRCRESAHA.112.300154

46. Ahamed J, Burg N, Yoshinaga K, Janczak CA, RIFKIN DB, COLLER BS. In vitro and in vivo evidence for shear-induced activation of latent transforming growth factor- 1 . Blood 2008; 1: 3650-3660. https://doi.org/10.1182/ blood-2008-04-151753

47. Bobrowska B, Wieczorek-Surdacka E, Kruszelnicka O, Chyrchel B, Surdacki A, Dudek D. Clinical correlates and prognostic value of plasma galectin-3 levels in degenerative aortic stenosis: a single-center prospective study of patients referred for invasive treatment. Int J Mol Sci 2017; 29: 947. https://doi.org/10.3390/ ijms 18050947

48. BäCK M, Gasser TC, Michel J-B, Caligiuri G. Biomechanical factors in the biology of aortic wall and aortic valve diseases. Cardiovasc Res 2013; 15: 232-241. https://doi.org/10.1093/ cvr/cvt040

49. Sádaba JR, Martínez-Martínez E, Arrieta V, Álvarez V, Fernández-Celis A, Ibarrola J et al. Role for galectin-3 in calcific aortic valve stenosis. J Am Heart Assoc 2016; 4. https://doi. org/10.1161/JAHA.116.004360
50. Cioffi G, Faggiano P, Vizzardi E, Tarantini L, CraMARIUC D, GerdTs E et al. Prognostic effect of inappropriately high left ventricular mass in asymptomatic severe aortic stenosis. Heart 2011; 15: 301-330. https://doi.org/10.1136/ hrt.2010.192997

51. Arrieta V, Martinez-Martinez E, Ibarrola J, AlvaREZ V, SÁdABA R, GARCiA-PEÑa A et al. A role for galectin-3 in the development of early molecular alterations in short-term aortic stenosis. Clin Sci (Lond) 2017; 1: 935-949. https://doi. org/10.1042/CS20170145

52. Wu CK, Su MY, LeE JK, Chiang FT, Hwang JJ, Lin JL et al. Galectin-3 level and the severity of cardiac diastolic dysfunction using cellular and animal models and clinical indices. Sci Rep 2015; 5: 17007. https://doi.org/10.1038/ srep 17007

53. Zhou K, Zhou Y, Zhao Y, Tan C, Yuan Z, Li J et al. The relationship between galectin-3 and different patterns of ventricular geometry remodelling in aortic valve stenosis. Heart Lung Circ 2016; 25: 371-377. https://doi. org/10.1016/j.hlc.2015.08.021

54. Baldenhofer G, Zhang K, Spethmann S, Laule M, EILERS B, LEONHARDT F et al. Galectin-3 predicts short- and long-term outcome in patients undergoing transcatheter aortic valve implantation (TAVI). Int J Cardiol 2014; 20: 912-917. https://doi.org/10.1016/j.ijcard.2014.10.010

55. Calvier L, Martinez-Martinez E, Miana M, Cachofeiro V, Rousseau E, SÁdaba JR et al. The impact of galectin-3 inhibition on aldosterone-induced cardiac and renal injuries. JACC Heart Fail 2015; 3: 59-67. https://doi.org/10.1016/j. jchf.2014.08.002

56. Ibarrola J, Martínez-Martínez E, Sádaba JR, Arrieta V, García-Peña A, Álvarez V et al. Beneficial effects of galectin-3 blockade in vascular and aortic valve alterations in an experimental pressure overload model. Int J Mol Sci 2017; 31: 1664. https://doi.org/10.3390/ ijms 18081664

57. Lala Ri, Darabantiu D, Pilat L, Puschita M. Galectin-3: A Link between myocardial and arterial stiffening in patients with acute decompensated heart failure? Arq Bras Cardiol 2016; 25: 121-129. https://doi.org/10.5935/ abc. 20150149 